This is an author produced version of a paper published in British Journal of Dermatology. This paper has been peer-reviewed but does not include the final publisher proof-corrections or journal pagination.

Citation for the published paper:

Carlsson, C P and Sundler, F and Wallengren, J. "Cutaneous innervation before and after one treatment period of acupuncture."

British Journal of Dermatology, 2006, Vol: 155, Issue: 5, pp. 970-6. http://dx.doi.org/10.1111/j.1365-2133.2006.07450.x

Access to the published version may require journal subscription. Published with permission from: Blackwell 


\section{Cutaneous innervation before and after one treatment period of acupuncture}

Christer P. Carlsson, MD, PhD, ${ }^{*}$ Frank Sundler, $\mathrm{PhD} \uparrow$ and Joanna Wallengren, $\mathrm{MD}, \mathrm{PhD} \uparrow$ Clinical Science, Dept of Neurosurgery, ${ }^{*}$, Experimental Medical Science, Section for Neuroendocrine Cell Biology, $\uparrow$, and Clinical Science, Department of Dermatology, $\downarrow$ Lund University, University Hospital, Lund, Sweden

Address:

Joanna Wallengren, $\mathrm{MD}, \mathrm{PhD}$

Department of Dermatology, Lund University

University Hospital

SE-221 85 Lund

Sweden

Joanna.Wallengren@derm.lu.se

Tel: +46 46173151

Fax: +46 46173947

\section{Short title:}

Acupuncture and cutaneous innervation

Key words

Skin, acupuncture, peripheral nerve, CGRP, PGP 9.5, VR1

\section{Conflicts of interest}

None declared. 


\section{Summary}

Background The effect of acupuncture on nociceptive pain is well documented, but effects on nociceptive itch have been contradictory.

Objectives To evaluate possible effects of acupuncture on the occurrence, distribution and function of sensory nerve fibres in human skin.

Methods Ten subjects were treated by inserting ten acupuncture needles subcutaneously in the upper-lateral aspect of one buttock. The subjects were recruited from an acupuncture clinic and were undergoing specific acupuncture treatment for their disorders. The needles were stimulated (rotated to and fro) twice during the twice-weekly 25-minute sessions over five weeks. Skin biopsies, diameter $3 \mathrm{~mm}$, were taken before and 3 to 6 days after local acupuncture. Antibodies against pan-neuronal marker, PGP 9.5, calcitonin gene-related peptide, CGRP, vanilloid receptor VR1 and $\mu$-and $\delta$-opioid receptors were employed to study sensory unmyelinated nerve fibres that transmit nociceptive pain and itch. A histamine prick test using planimetry was used to record experimental itch after acupuncture on the treated area and on the corresponding control skin respectively, and a visual analogue scale was used to evaluate itch.

Results The number of CGRP nerve fibres/ biopsy sectionwas reduced from $36.0 \pm 3.3$ to $21.3+4.0(p=0.05)$ after the treatment. The PGP 9.5-immunoreactive nerve fibres/ biopsy were found both in the epidermis and in subpapillary dermis. The total number of PGP 9.5 immunoreactive nerve fibres $249.8 \pm 16.7$ to $211.8 \pm 12.0(\mathrm{p}=0.03)$. The PGP 9.5 immunoreactive nerve fibres occurring in the dermis appeared more fragmented after the acupuncture compared to pre-treatment. The VR 1 immunoreactivity was found both in the free nerve fibres and in kite-like formations, possibly mast cells, throughout the 
dermis, sometimes occurring around hair follicles. The number of VR1 immunoreactive elements was not significantly influenced by the acupuncture, $33.5+4.6$ vs $43.0 \pm 4.4$ $(\mathrm{p}=0.09)$. No immunoreactivity was found in the skin against $\mu$-and $\delta$-opioid receptors with the antibodies used in this study. Neither histamine-induced itch nor cutaneous responses were influenced by acupuncture.

Conclusions The present data indicates an effect of acupuncture on neuropathic itch but not histamine-mediated itch. Our findings support the opinion that the pain-relieving effects of acupuncture partly depend on its effect on the peripheral innervation.

\section{Introduction}

Needle acupuncture is traditional Chinese art of healing, about 3000 years old, for the treatment of certain diseases and symptoms. Thin needles are inserted through the skin to varying depths, often into the underlying muscle, here called "muscle acupuncture." Many modifications of the method have been described and the concept of acupuncture is not well defined. ${ }^{1}$

There is now reasonable evidence that acupuncture has a clinically relevant painrelieving effect on certain forms of chronic nociceptive pain., ${ }^{2,3,4,5}$ Acupuncture also seems to affect the function of the autonomic nervous system in various ways. For example, peripheral circulation increases after acupuncture, ${ }^{6}$ nausea and vomiting can be relieved, and salivary flow rates can be improved in patients with different forms of xerostomia. ${ }^{7,8}$

Several physiological mechanisms have been suggested for the pain-relieving effect of acupuncture. Spinal and supraspinal endorphin release has been proposed, as has the 
involvement of other transmitters like serotonin and norepinephrine. ${ }^{9,}{ }^{10}$ In addition to the central neurochemical changes there are also peripheral changes after acupuncture. The insertion of a needle into the tissues induces direct changes close to the needle (in all different tissues penetrated) and through axon reflexes. The flare reaction (reddening, vasodilatation) is often seen locally around the acupuncture needles. This vasodilatation in the skin, due to axon reflexes, has been recognised for a very long time and the mechanisms have been clarified in detail. ${ }^{11}$ The stimulation of $\mathrm{A} \delta$ or $\mathrm{C}$ fibres releases vasoactive and pro-inflammatory neuropeptides (e.g. CGRP, SP, NKA, opioids, galanin, somatostatin and VIP). It has been shown that the concentration of the neuropeptides VIP and CGRP in saliva from xerostomic patients increases after acupuncture. ${ }^{12}$

Opiate receptors have been found on nociceptive afferents in inflammatory conditions. ${ }^{13}$ The different endorphins are secreted from inflammatory cells in the tissue after an injury. ${ }^{13}$ This accumulation may lead to a peripheral opioid analgesia some days after an injury and might be initiated by acupuncture needles in the tissue. ${ }^{14}$ In a recent retrospective study, symptomatic relief of neuropathic pruritus was reported in 12 of 16 patients treated with acupuncture. ${ }^{15}$ Twelve patients had symptoms of brachioradial pruritus, seven of notalgia paresthetica and four of meralgia paresthetica. Relapse occurred in $37 \%$ of patients within 1-12 months following treatment. Localized neuropathic itch such as notalgia paresthetica, brachioradial pruritus and other peripheral neuropathies display aberrant sensory innervation. ${ }^{16,17}$ The question is whether this sensory innervation may be a target for acupuncture. In other words, does acupuncture exert any effects on sensory nerve fibres in the skin? We addressed this question by studying skin biopsies from gluteal uninvolved skin before 
and a few days after acupuncture treatments. Antibodies against pan-neuronal marker, PGP 9.5 and calcitonin gene-related peptide, CGRP, served to evaluate sensory innervation in the skin. Immunohistochemical markers for a thermoreceptor, vanilloidreceptor, VR1 (capsaicin- receptor), and $\mu$-and $\delta$-opioidreceptors responsible for perception of pain respectively were employed to study sensory unmyelinated nerve fibres that transmit nociceptive itch and pain. Histamine induced flare, wheal and itch were recorded in order to evaluate the function of the sensory nerve fibres after acupuncture.

\section{Materials and methods}

\section{Patients and procedures}

Ten patients were treated with acupuncture because of pain or other dysfunctional disorder. All patients were women and their mean age was 55, with a range from 31 to 75 years. Table 1 shows a summary of information concerning the age, and treatment diagnosis. Muscle acupuncture was used and all patients responded well to the treatment given. Therapeutical acupuncture needles were not inserted in the area used experimentally in this study.

In each session, the patients were given their normal acupuncture treatment first and then the experimental procedure. This consisted of ten acupuncture needles subcutaneously (to a depth of about about $10 \mathrm{~mm}$ ) in a circle with a diameter of about $20 \mathrm{~mm}$. The needles were $0.30 \mathrm{~mm}$ thick and $30 \mathrm{~mm}$ in length. All needles were inserted in the same upper-lateral aspect of one buttock. No needle sensation, de-qi feeling (numbness, slight pain), was searched for. The needles were stimulated (rotated to and fro) twice during the 
25-minute sessions. Punch biopsies ( $3 \mathrm{~mm}$ in diameter) were taken from the upper, lateral aspect of one buttock one week before the local acupuncture. The needles were inserted 1 $\mathrm{cm}$ around the first punch biopsy. Acupuncture was then applied twice weekly for 5 weeks. The second biopsy was taken from the skin of the buttocks, some distance from the scar after the first biopsy, 3-6 days after the tenth local acupuncture treatment. Informed consent was obtained in all cases. The study was approved by the Ethics Committee of the Lund University Medical Faculty and has been conducted according to Declaration of Helsinki principles.

\section{Processing of biopsies}

The biopsies were fixed by immersion overnight in a mixture of $2 \%$ formaldehyde and $0.2 \%$ picric acid solution in a $0.1 \mathrm{~mol} / 1$ phosphate buffer $(\mathrm{pH} 7.2)$ and then thoroughly rinsed in a Tyrode solution containing $10 \%$ sucrose. They were then frozen on dry ice, after which $10 \mu \mathrm{m}$ thick sections were cut serially in a cryostat. The sections were then processed for immunocytochemistry, using antibodies against the neuropeptide calcitonin gene-related peptide (CGRP) and the pan-neuronal marker PGP 9.5. The antibodies against CGRP, raised in guinea pig (working dilution 1: 1200, Euro Diagnostica, Malmö, Sweden), were used to demonstrate the thin sensory C-fibres. ${ }^{18}$ The PGP 9.5 antibodies (working dilution 1:200, Ultraclone, Cambridge, UK) were used to visualize the various cutaneous nerve fibres. PGP 9.5 is a cytoplasmic constituent present in all parts of the neuron, and in both the cell body and all the processes. Data on the specificity of the antibodies employed has been presented elsewhere. ${ }^{18}$ Antibodies against the vanilloid receptor VR 1, which were raised in rabbit (working dilution 1: 600, Euro Diagnostica, 
Malmö, Sweden), were used to identify capsaicin-sensitive structures. ${ }^{18}$ Vanilloid capsaicin, the major pungent agent contained in hot pepper, is known to release neuropeptides from sensory nerve fibres. ${ }^{19}$ No fluorescence was detected in preabsorption tests with excess amount of homologous antigen (100 microgram of synthetic peptide per $\mathrm{ml}$ antiserum at working dilution).

Antibodies against $\mu$ - and $\delta$-opioid receptors were raised in rabbit (working dilution for $\mu$-opioid-receptors 1:200 and 1: 400, for $\delta$-opioid-receptors 1: 400 and 1. 800, ImmunoStar Inc, Hudson, WI, USA). ${ }^{20,21}$

Three consecutive sections of each of the biopsies were studied. The microscope used was a Leica Aristoplan epifluorescence. The number of immunoreactive nerve fibres in the epidermis and the dermis was assessed visually at magnification of $x 250$. All the immunopositive nerve fibre fragments in the whole biopsy section were counted. Blind evaluation of the biopsies was performed by a single observer. Micrographs were taken using Kodak Tri-X 400 film.

\section{Histamine responses}

In five individuals (No 5, 7, 8, 9, 10 in Table I), histamine (Soluprick ${ }^{\mathrm{R}}, \mathrm{ALK}$, Denmark) was 'pricked' into the area treated by acupuncture on the upper lateral aspect of the buttock and on the other corresponding, untreated side. Evaluation regarding erythema and infiltration was made after 5 and 20 minutes resp using planimetry. In addition, itch evoked by histamine was evaluated after 5 minutes using $\mathrm{VAS}^{22}$

\section{Statistical analysis}

Statistical evaluation was based on the mean of the counts in the three sections taken 
from each of the ten patients before and after the treatment respectively. Results are expressed as mean \pm SEM. Wilcoxon signed ranks test was used for comparing the skin biopsies before and after all treatments.

\section{Results}

\section{Skin biopsies}

CGRP-immunoreactive nerve fibres were mostly localized in subpapillary dermis and only occasionally found in the epidermis (Figure $1 \mathrm{a}, 1 \mathrm{~b}$ ). The number of CGRP nerve fibres was reduced from $36.0 \pm 3.3$ to $21.3 \pm 4(\mathrm{p}=0.005)$ after the treatment (Figure $4 \mathrm{a})$. The PGP 9.5-immunoreactive nerve fibres were found both in the epidermis and in subpapillary dermis (Figure $2 \mathrm{a}, 2 \mathrm{~b}$ ). The number of PGP 9.5-immunoreactive nerve fibres in the biopsies was significantly reduced from $249.8 \pm 16.7$ to $211.8 \pm 12.0(p=0.03)$ (Figure 4b).

The VR 1 immunoreactivity was found both in free nerve fibres and in kite-like formations throughout the dermis, sometimes occurring around hair follicles (Figure 3a, b). The number of VR1 immunoreactive nerve fibres seemed to be amplified by the acupuncture from $33.5 \pm 4.6$ to $43.0 \pm 4.4(\mathrm{p}=0.09)$, after the treatment (Figure $4 \mathrm{a})$. There was no immunoreactivity in the skin seen with antibodies against $\mu$-and $\delta$-opioid receptors used in this study although they were capable of demonstrating neuronal elements in dorsal horn of the rat spinal cord; $\delta$-opioid receptors present in nerve fibers and $\mu$-opioid receptors in nerve cell bodies (unpublished observations). The immunohistochemical data are summarised in Table 2. 


\section{Histamine reaction}

Repeated acupuncture did not influence prick test reactions to histamine. The mean flare reaction on the treated skin was $8.6 \pm 4.6 \mathrm{~cm}^{2}$ compared to $8.2 \pm 4.4 \mathrm{~cm}^{2}$ on the control side. The mean wheal response was $0.8+0.1 \mathrm{~cm}^{2}$ vs $0.9 \pm 0.5 \mathrm{~cm}^{2}$ on the control side. The histamine-evoked itch (VAS) was $24 \%$ vs $18 \%$ on the control side.

\section{Discussion}

We have shown that the innervation of the skin using a pan-neuronal marker PGP 9.5 was reduced after a treatment period of ten acupuncture sessions. The density of CGRPimmunoreactive nerve fibres, representing sensory innervation in the skin, was also reduced after the treatments. Such a reduction of sensory nerve fibres conducting the itch sensation may help to reduce itch. A proliferation and sprouting of cutaneous nerve fibres has been found in some conditions of itch such as notalgia paresthetica and in pruritus of uremia respectively. ${ }^{23,24}$ Our findings would explain the symptomatic relief of local pruritus reported in 12 of 16 patients treated with acupuncture. ${ }^{15}$

A reduction of cutaneous nerve fibres was found after other treatments of itch such as topical capsaicin or phototherapy. ${ }^{25,26}$ Another treatment of itch that has been developed recently is cutaneous field stimulation (CFS), which activates C-fibres electrically and induces a reduction of intraepidermal PGP 9.5 nerve fibres only, leaving the intradermal fibres unaffected. ${ }^{27}$ The difference between acupuncture and CFS in their effects on cutaneous innervation may be explained by the respective positions of the needles and electrodes. While acupuncture needles in this study were positioned subcutaneously, 15$20 \mathrm{~mm}$ deep, the electrodes of CFS are $2 \mathrm{~mm}$ long and protrude mainly into the epidermis 
when the flexible rubber plate is applied to the skin.

VR1 immunoreactivity was found both at free nerve fibres and in kite-like structures in dermis. Although not confirmed by a routine histology or specific markers, the form and distribution of the VR1 immunoreactive cells around the hair follicles suggest that they are mast cells. ${ }^{28}$ The number of VR1-IR structures, including nerve fibres and mast cells, in the skin was not influenced significantly by acupuncture. This finding is in accordance with a previous study on the effects of phototherapy on cutaneous innervation. ${ }^{26} \mathrm{~A}$ reduction of VR1 immunoreactve nerve fibres might be expected, as the number of sensory CGRP-IR nerve fibres was reduced, and VR1 co-localized with the neurotransmitters such as CGRP and substance $\mathrm{P} .{ }^{29,30}$ that only a subpopulation of VR1IR nerve fibres are identical with CGRP-IR nerve fibres. ${ }^{26}$

As the respective numbers of epidermal and dermal nerve fibres were reduced, a reduction in the axon reflexes, such as the flare reaction to histamine prick test, might be expected. In this study histamine-induced responses, including itch, did not seem to be influenced by acupuncture. This finding should, however, be interpreted with some caution because we only tested five patients. This contrasts with a recently published study where a single acupuncture inhibited the wheal and itch but not flare induced by histamine. ${ }^{31}$ An effect on itch would imply an inhibition of the nerve conduction and the axon reflex resulting in flare, while wheal, on the other hand, is an effect of vascular permeability. ${ }^{32}$ Nerve blockade, using anaesthetics like Xylocain, almost totally inhibits the flare reaction to histamine while its effect on wheal is only partial. ${ }^{32}$ In the present study we were interested in the effects of serial acupuncture on local cutaneous innervation, which may have implications for treatment of itch. However, all the patients 
had undergone acupuncture at other sites (Table 2), possibly adding general effects on itch and explaining why there was no difference between the two sides. Such effects may be explained by generation of endogenous opioid peptides in several organ systems. However, we failed to find any immunoreactivity in the skin toward $\mu$-and $\delta$-opioid receptors used, although the antibodies used gave positive immunostaining in the rat spinal cord. An occurrence of an isomer of a $\mu$-receptor, 1A, in human skin and of a $\delta$ opioid receptor in rat skin has been reported previously. ${ }^{33,34}$ In both these studies, the immunoreactive opioid receptors were confined to sensory nerve fibres, co-existing with CGRP. ${ }^{33,34}$ Further studies are needed to localize opioid receptors in human skin. Our finding of a local effect of acupuncture on peripheral innervation casts new light on the clinically relevant pain-relieving effect of acupuncture on chronic nociceptive pain. ${ }^{2,3,4,5}$ In some painful nociceptive conditions, such as osteoarthritis (of the hip joint), endometriosis, rotator cuff syndrome (of coracoacromial ligament) or Achilles tendinosis, density of peripheral nerve fibres has been shown to be increased compared to normal, non-inflamed tissue. ${ }^{34,35,36,37,38}$ A reduction of peripheral nerve fibre density where the needles are inserted locally at the pain-generating process might be one explanation for the pain-relieving effects in nociceptive pain conditions. On the other hand acupuncture has no better effect than placebo on different forms of neuropathic pain. ${ }^{2}$ A possible explanation would be that peripheral nerve density is reduced in some forms of neuropathic pain, such as diabetes neuropathy, burning mouth syndrome, and HIVassociated sensory neuropathy ${ }^{40,41,42}$ In conclusion, we found a reduction of the cutaneous CGRP and PGP 9.5 immunoreactive nerve fibre density following serial acupuncture in ten treatments. This 
finding would explain the alleviation of nociceptive pain and indicate an effect of acupuncture on itch conditions associated with proliferation of sensory nerve fibres. The VR1-immunoreactivity, mainly confined to nerve fibres and mast cells, was not significantly changed by acupuncture. It may explain why repeated acupuncture influenced neither the itch nor the size of prick test reactions to histamine in this study. It seems, however, that acupuncture may be used to treat neuropathic itch. Our findings might also give rise to more research concerning peripheral mechanisms of acupuncture.

\section{Acknowledgements}

The study was supported by the Welander and Finsen Foundation. We are grateful to Mrs. Doris Persson, Department of Experimental Medical Science, Section for Neuroendocrine Cell Biology, for technical assistance with immunocytochemistry.

\section{References}

1. Kaptchuk T.J. Acupuncture: Theory, efficacy and practice. Ann. Intern. Med. 2002; $136: 374-383$.

2. Carlsson C, Sjölund B. Acupuncture and subtypes of chronic pain: assessment of longterm results. Clin. J. Pain 1994; 10: 290-295.

3. Manheimer E, White A, Berman B, Forys K, Ernst E. Meta-analysis: acupuncture for low back pain. Ann. Intern. Med. 2005;142(8):651-63.

4. Linde K, Streng A, Jurgens S, Hoppe A, Brinkhaus B, Witt C, Wagenpfeil S, Pfaffenrath V, Hammes MG, Weidenhammer W, Willich SN, Melchart D. Acupuncture for patients with migraine: a randomized controlled trial. JAMA. 2005; 293(17):2118-25. 
5. Vickers AJ, Rees RW, Zollman CE, McCarney R, Smith CM, Ellis N, Fisher P, Van Haselen R. Acupuncture for chronic headache in primary care: large, pragmatic, randomised trial. BMJ. 2004;328(7442):744.

6. Jansen G, Lundeberg T, Samuelson U.E, Thomas M. Increased survival of ischaemic musculocutaneous flaps in rats after acupuncture. Acta Physiol. Scand. 1989; 135:555558.

7. Vickers A.J. Can acupuncture have specific effects on health? A systematic review of acupuncture antiemesis trials. Journal of the Royal Society of Medicine 1996; 89:303311.

8. Blom M, Dawidson I, Angmar-Månsson B. The effect of acupuncture on salivary flow rates in patients with xerostomia. Oral Surg. Oral Med. Oral Pathol. 1992; 73:293-298. 9. Price D.D, Mayer D.J. Evidence for endogenous opiate analgesic mechanisms triggered by somatosensory stimulation (including acupuncture) in humans. Pain Forum $1995 ; 4: 40-43$

10. Ulett G.A, Han S, Han J.S. Electroacupuncture: mechanisms and clinical application. Biol. Psychiatry 1998; 44: 129-138.

11. Maggi C.A. The pharmacology of the efferent function of sensory nerves. J. Aut. Pharm. 1991;11:173-208.

12. Dawidson I, Angmar-Månsson B, Blom M, Theodorsson E, Lundeberg T. The influence of sensory stimulation (acupuncture) on the release of neuropeptides in the saliva of health subjects. Life Sci. 1998a; 63: 659-674

13. Stein C, Yassouridis A. Peripheral morphine analgesia. Pain. 1997 ; 71:119-21.

14. Carlsson C. Acupuncture mechanisms for clinically relevant long-term effects 
- reconsideration and a hypothesis. Acupuncture in Medicine 2002; 20 (2-3):82-99

15. Stellon A. Neurogenic pruritus: an unrecognised problem? A retrospective case series of treatment by acupuncture. Acupunct. Med. 2002; 20 (4): 196-190. Springall D.R, Karanth S.S, Kirkham N, Darley C.R, Polak J.M. Symptoms of notalgia paresthetica may be explained by increased dermal innervation. Invest Dermatol. 1991; 97(3):555-61. 17. Wallengren J, Sundler F. Brachioradial pruritus is associated with a reduction of cutaneous inervation which normalizes during the symptom-free remissions. J. Am. Acad. Dermatol. 2005; 52: 142-145.

18. Wallengren J, Chen D, Sundler F. Neuropeptide-containing C-fibres and wound healing in rat skin. Neither capsaicin nor peripheral neurotomy affect the rate of healing. Br. J. Der.m 1999, 140, 400-408.

19. Caterina M.J, Julius D. The vanilloid receptor: a molecular gateway to the pain pathway. Annu. Rev. Neurosci. 2001, 24: 487-517.

20. U.Arvidsson, M. Riedl, S. Chakrabarti, J. Lee, A. Nakano, R. Dado, H. Loh, P. Law, M. Wessendorf, and R. Elde. Distribution and Targeting of a $\mu$ - Opioid Receptor (MOR1) in Brain and Spinal Cord. J. Neurosci. 1995; 15: 3328-3341.

21. Dado, R.J, Law, P.Y. Loh, H.H, and Elde, R. Immunofluorescent identification of a delta $(\delta)$-opioid receptor on primary afferent nerve terminals. NeuroReport 1993; 5: 341344.

22. Aithen R.C.B. Measurement of feelings using visual analogue scales. Proc. Soc. Med. 1969, 62: 989-993.

23. Springall DR, Karanth SS, Kirkham N, Darley CR, Polak JM. Symptoms of notalgia paresthetica may be explained by increased dermal innervation. J. Invest. Dermatol. 
1991; 97: 555-61..

24. Johansson O, Hilliges M, Stahle-Backdahl M. Intraepidermal neuron-specific enolase (NSE)-immunoreactive nerve fibres: evidence for sprouting in uremic patients on maintenance hemodialysis. Neurosci. Lett. 1989;99(3):281-6.

25. Wallengren J, Chen D. Local skin lesions in rat after subcutaneous deposition of capsaicin. Skin Pharmacology and Applied Skin Physiology 2002; 15(3); 147-158.

26. Wallengren J, Sundler F. Phototherapy induces loss of epidermal and dermal nerve fibres. Acta Derm. Venereol. (Stockh) 2004; 84: 111-115.

27. Wallengren J, Sundler F. Cutaneous field stimulation (CFS) in treatment of severe localized itch. Arch. Dermatol. 2001; 137: 1323-1325.

28. Stander S, Moormann C, Schumacher M, Buddenkotte J, Artuc M, Shpacovitch V, Brzoska T, Lippert U, Henz BM, Luger TA, Metze D, Steinhoff M. Expression of vanilloid receptor subtype 1 in cutaneous sensory nerve fibres, mast cells, and epithelial cells of appendage structures. Exp. Dermatol. 2004 Mar;13(3):129-39.

29. Hwang SJ, Valtschanoff JG. Vanilloid receptor VR1-positive afferents are distributed differently at different levels of the rat lumbar spinal cord. Neurosci Lett. 2003;349(1):41-4.

30._Dussor GO, Anthony AS, Gracia NB, Kilo S, Price TJ, Hargreave KM, Flores CM. Potentiation of evoked calcitonin gene-related peptide release from oral mucosa: a potential basis for the pro-inflammatory effects of nicotine. Eu J Neuroscience 2003; 18: $2515-2526$

31. Pfab F, Hammes M, Bäcker M, Huss-Marp J, Athanasiadis GI, Tölle TR, Behrendt H, Ring J, Darsow U. Preventive effect of acupuncture on histamine-induced itch: A 
blinded, randomized, placebo-controlled, crossover trial. J, Allergy and Clinical Immunol. 2005; 116: 1386-1388.

32._Wallengren J, Håkanson R. Effects of substance P, neurokinin A and calcitonin generelated peptide in human skin and their involvement in sensory mediated responses. Eu. J. Pharmacol. 1987; 143. 267-273.

33. Stander S, Gunzer M, Metze D, Luger T, Steinhoff M. Localization of mu-opioid receptor $1 \mathrm{~A}$ on sensory nerve fibres in human skin. Regul Pept. 2002;110(1):75-83. 34. Wenk HN, Honda CN. Immunohistochemical localization of delta opioid receptors in peripheral tissues. J Comp Neurol. 1999; 408(4):567-79.

35. Saxler G, Loer F, Skumavc M, Pfortner J, Hanesch U. Localization of SP- and CGRP-immunopositive nerve fibres in the hip joint of patients with painful osteoarthritis and of patients with painless failed total hip arthroplasties. Eur J Pain. 2006 Feb 3; 36. Tokushige N, Markham R, Russell P, Fraser IS. High density of small nerve fibres in the functional layer of the endometrium in women with endometriosis. Hum Reprod. 2006; 21(3):782-787.

37. Tamai M, Okajima S, Fushiki S, Hirasawa Y. Quantitative analysis of neural distribution in human coracoacromial ligaments. Clin Orthop Relat Res. 2000;373:125-34 38. Schubert TE, Weidler C, Lerch K, Hofstadter F, Straub RH. Achilles tendinosis is associated with sprouting of substance P positive nerve fibres. Ann Rheum Dis. 2005; 64(7):1083-6

39. Pittenger GL, Ray M, Burcus NI, McNulty P, Basta B, Vinik AI. Intraepidermal nerve fibres are indicators of small-fibre neuropathy in both diabetic and nondiabetic patients. Diabetes Care. 2004;27(8):1974-9 
40. Lauria G, Majorana A, Borgna M, Lombardi R, Penza P, Padovani A, Sapelli P. Trigeminal small-fibre sensory neuropathy causes burning mouth syndrome. Pain. 2005;115(3):332-7.

41. Polydefkis M, Yiannoutsos CT, Cohen BA,Hollander H, Schifitto G, Clifford DB, Simpson DM, Katzenstein D, Shriver S, Hauer P, Brown A, Haidich AB, Moo L, McArthur JC. Reduced intraepidermal nerve fibre density in HIV-associated sensory neuropathy. Neurology. 2002;58(1):115-9

\section{Legends}

1. Skin biopsies from patient 4 taken prior to (a) and after (b) serial acupuncture resp immunostained for PGP-9.5. The total cutaneous innervation shown. The PGPimmunoreactive nerve fibres are distributed both in the epidermis and dermis (a), and the number is reduced after the treatments (b).Magnification x 175 (a) and x 250 (b) respectively. The arrows show examples of nerve fibers.

2. Skin biopsies from patient 6 taken prior to (a) and after (b) serial acupuncture respectively, immunostained for CGRP, and showing sensory innervation. The number of both intraepidermal and dermal nerve fibres is reduced after acupuncture. Magnification x 175 (a) and x 250 (b) respectively. The arrows show examples of nerve fibers.

3. Skin biopsies from patient 8 taken prior to (a) and after (b) serial acupuncture ectively, and immunostained for capsaicin receptor, VR1. The arrows show distribution on mast cells $(a, b)$ and free nerve fibres (b). Magnification x $175(a, b)$.

4. Nerve fibre density in $3 \mathrm{~mm}$ punch biopsies from skin before and after 10 treatments with acupuncture. The mean number of CGRP-IR nerve fibres $( \pm$ SEM) found after 
acupuncture is reduced compared to the number before the treatment, $p=0.005$ (a). The density of VR1-IR structures $\left({ }_{-} \mathrm{SEM}\right)$ including both mast cells and nerve fibres found prior to and after acupuncture is not significantly altered $(p=0.09)$ (a). The number of PGP-IR nerve fibres $(\stackrel{+}{\mathrm{SEM}})$ found after acupuncture is reduced compared to the number prior to the treatment, $\mathrm{p}=0.03(\mathrm{~b})$. 


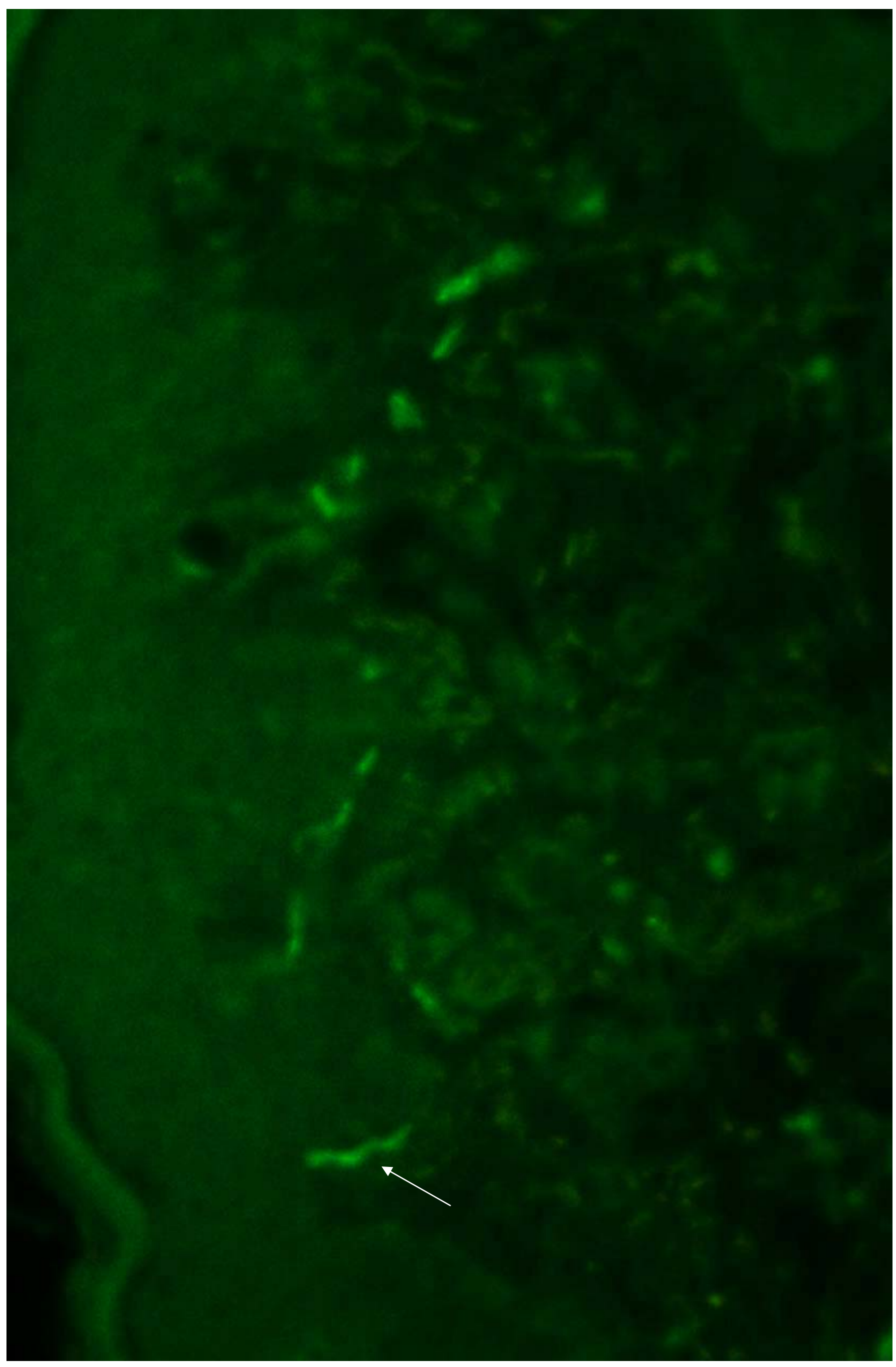




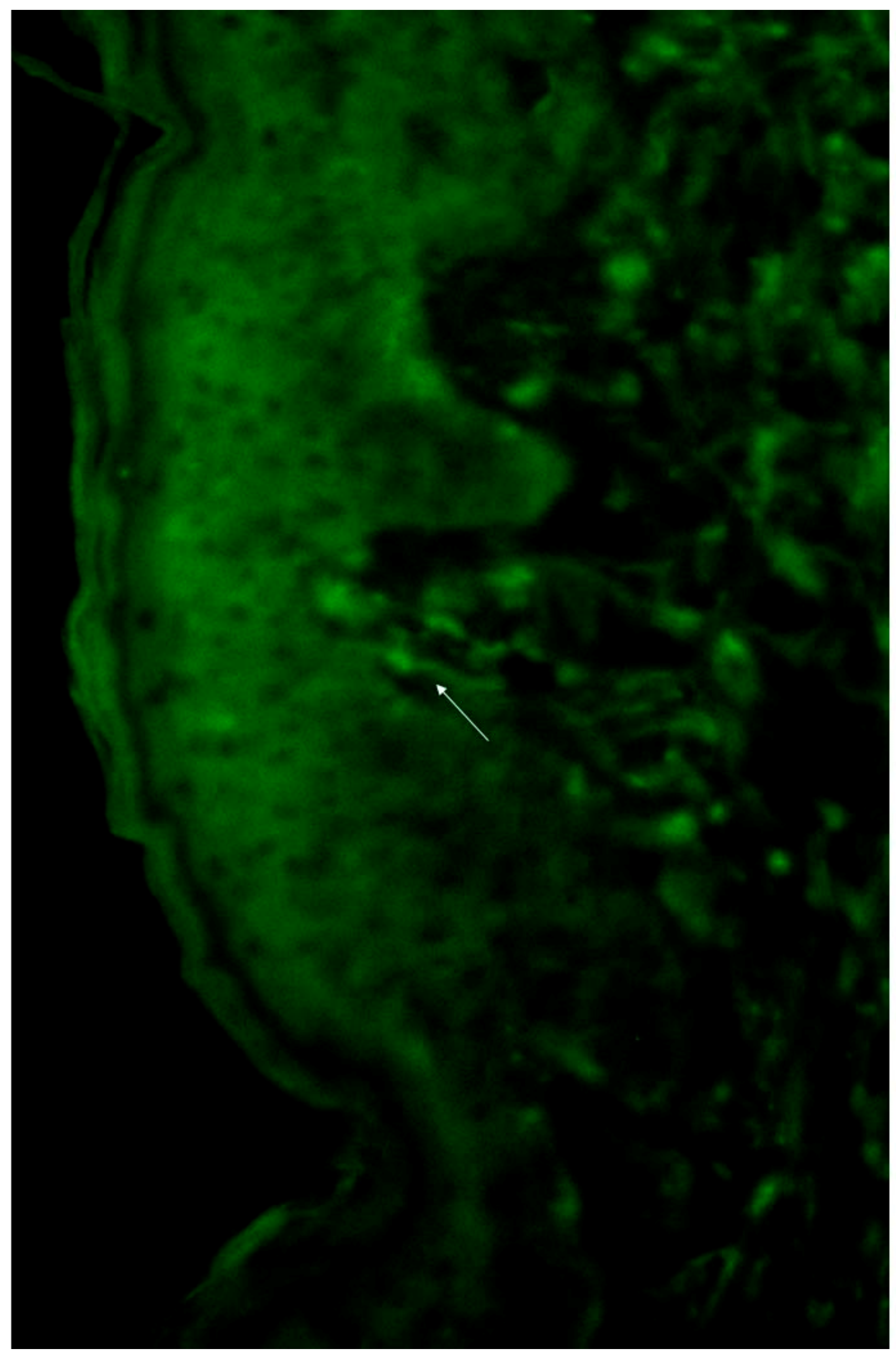




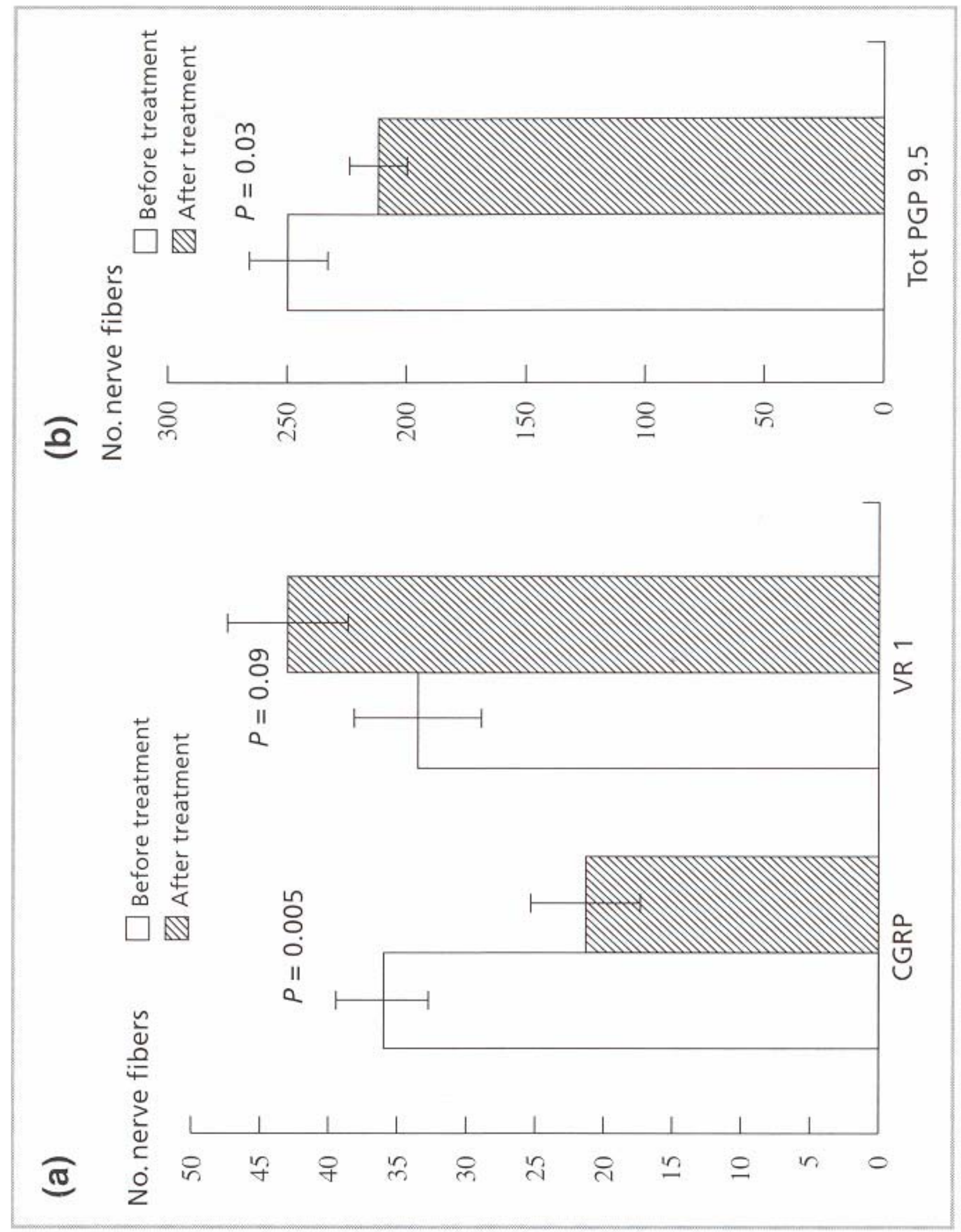




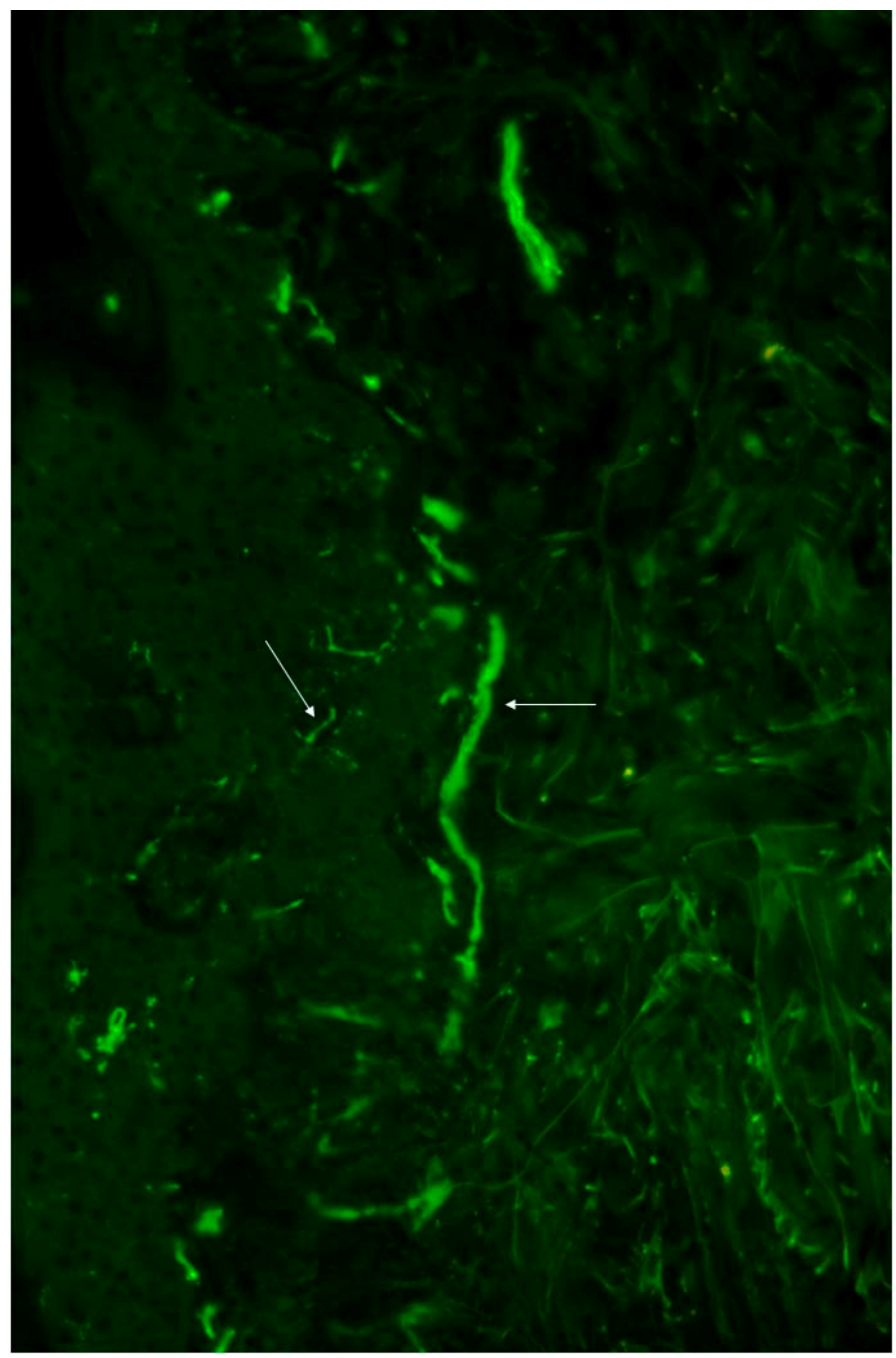




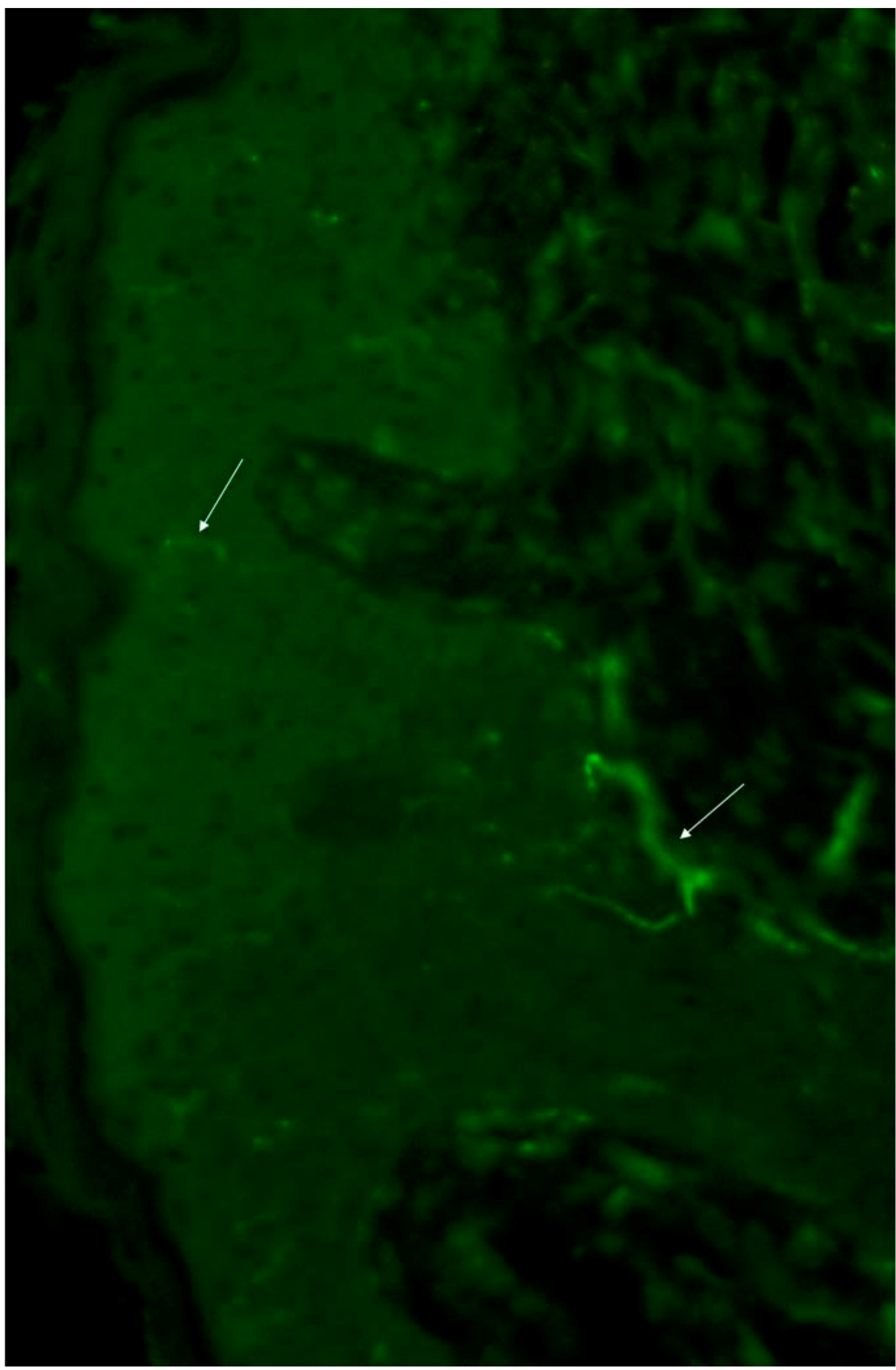




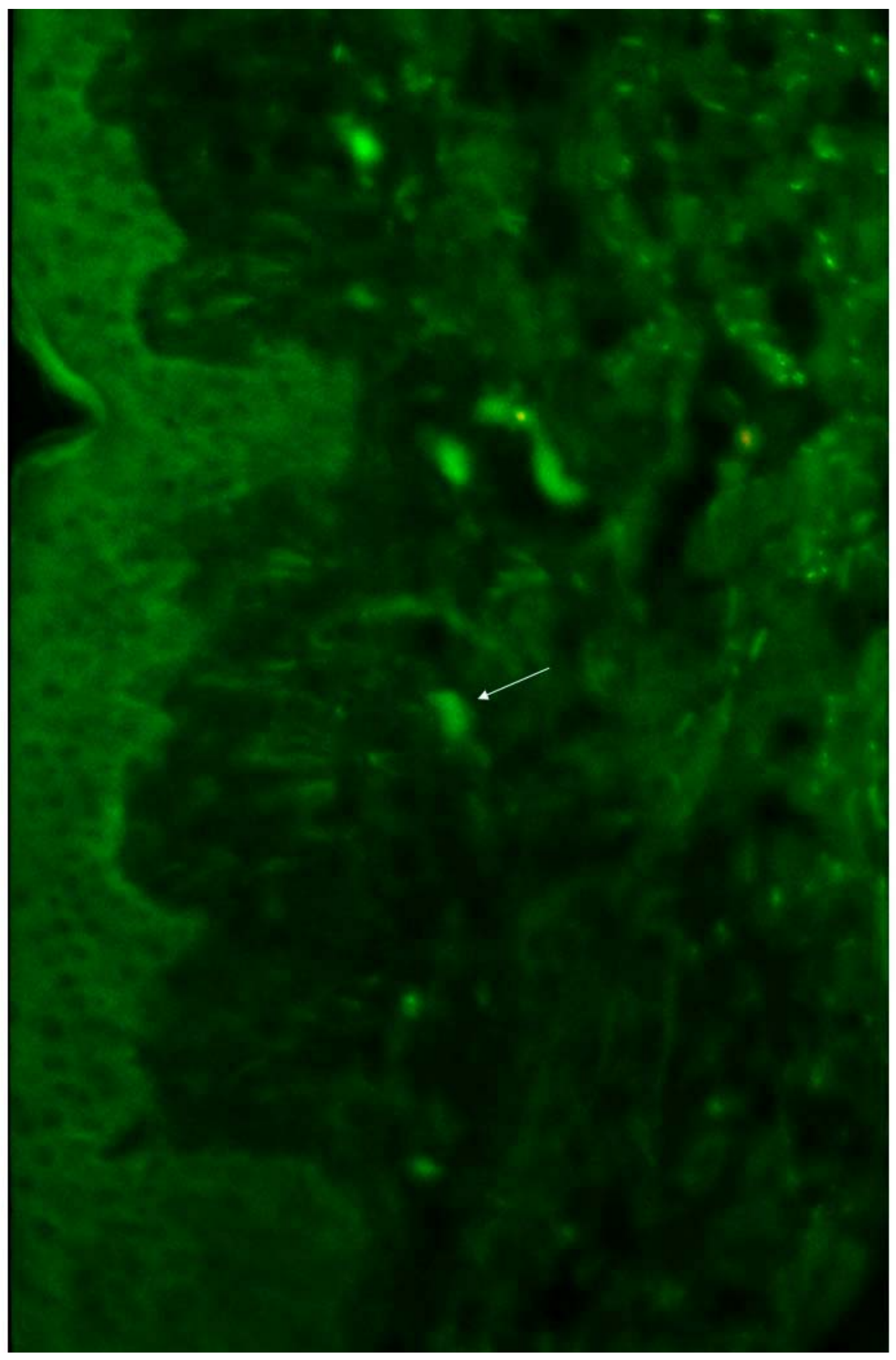




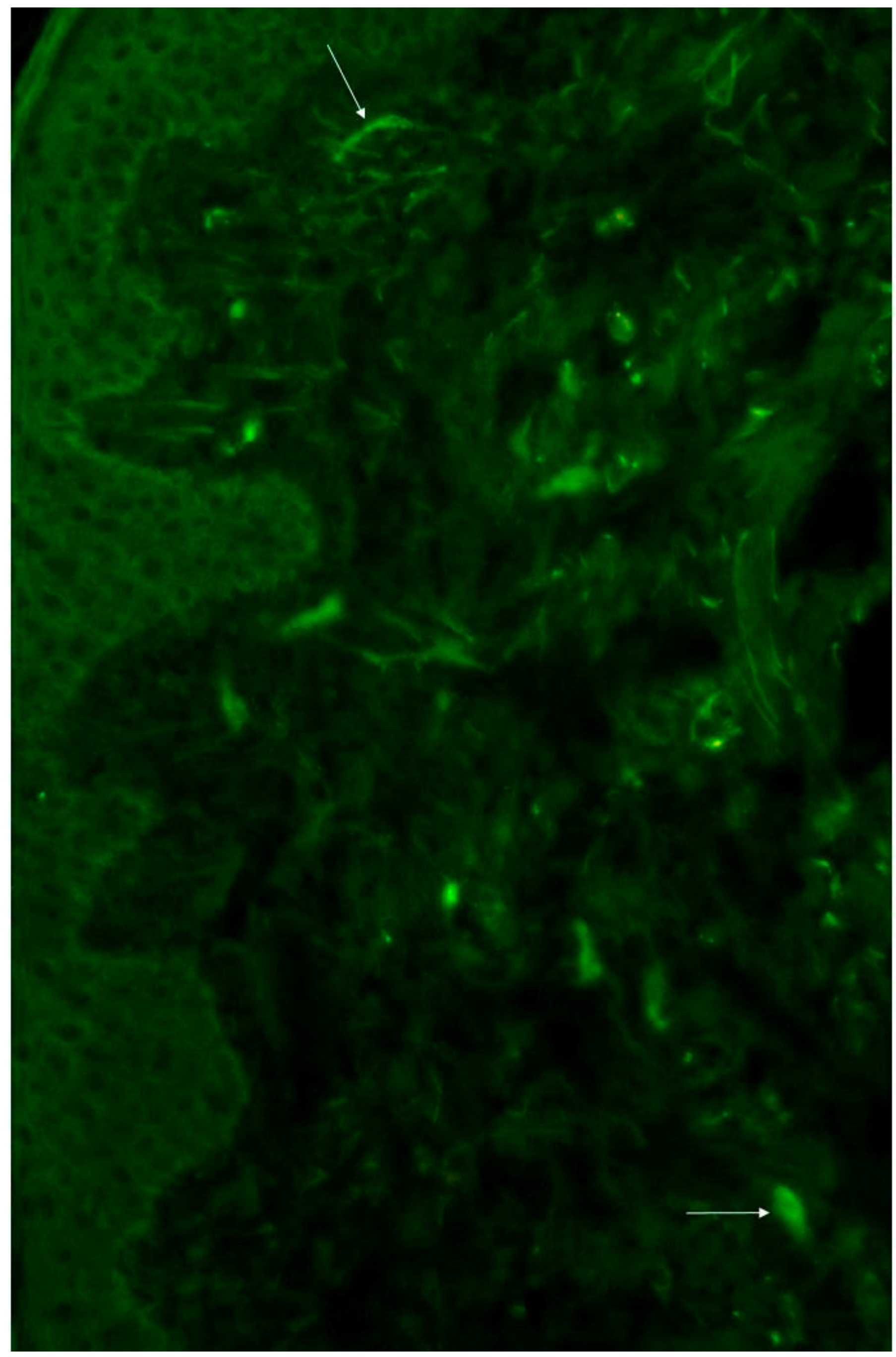

